PontIFícIA UNIVERSIDADE CATÓLICA dO RIO DE JANEIRO

Caminhos da Inovação em Café no Brasil Análise de Possibilidades com Foco na Zona da Mata Mineira

Pedro Vieira Soares Lomar

Trabalho de Conclusão de Curso

Centro de ciências socials - CCS

DePARTAMENTO de AdMINISTRAÇÃo

Graduação em Administração de Empresas 


\section{Caminhos da Inovação em Café no Brasil - Análise de Possibilidades com Foco na Zona da Mata Mineira}

Trabalho de Conclusão de Curso

Trabalho de Conclusão de Curso, apresentado ao programa de graduação em Administração da PUC-Rio como requisito parcial para a obtenção do titulo de graduação em Administração.

Orientadora: Maria Angela Campelo de Melo

Rio de Janeiro

Novembro 2017. 


\section{Agradecimentos}

Gostaria de agradecer a todos aqueles que me ajudaram a atingir esse objetivo.

Primeiramente, a Luiz e Adriana, meus pais e amigos, que durante toda a minha vida me apoiaram de diversas maneiras sempre que precisei. Um dia espero retribuir a todos seus gestos.

Aos vários amigos que mantive de diferentes etapas da vida, que sempre colaboraram para fazer de nossa jornada de crescimento um exercício mais prazeroso.

Aos companheiros de trabalho que tive durante minha curta vida profissional, que foram sempre atenciosos e me proporcionaram um ambiente prático de evolução pessoal e técnica.

Aos colegas de PUC-Rio, alunos, colaboradores e professores, que estiveram comigo nos últimos cinco anos estimulando nosso aprendizado e construção de conhecimento.

Por fim, gostaria de agradecer a professora Maria Angela Campelo de Melo em disponibilizar seu tempo para me ajudar na construção do trabalho com toda a dedicação que lhe é comum. Sinto que não poderia ter tido uma orientação melhor. 


\title{
Resumo
}

Lomar, Pedro Vieira Soares. Caminhos da Inovação em Café no Brasil Análise de Possibilidades com Foco na Zona da Mata Mineira. Rio de Janeiro, 2017. 43 p. Trabalho de Conclusão de Curso - Departamento de Administração. Pontifícia Universidade Católica do Rio de Janeiro.

Esse trabalho analisa o cenário atual de inovação de café no Brasil, focando no Consórcio de Pesquisa de Café, um arranjo de instituições que centraliza a pesquisa, a transferência de tecnologia e o financiamento para essa commodity. Além disso, o trabalho presta especial atenção para a situação na Zona da Mata Mineira, uma das regiões de produção de café mais importantes do Brasil. Por fim, o trabalho propõe mudanças em políticas públicas que podem tornar a inovação em café mais efetiva e com maior criação de valor, com maior participação de organizações relacionadas ao setor industrial, de comércio e de exportação.

Palavras-chave: Café, agronegócio, inovação, Minas Gerais, Zona da Mata.

\begin{abstract}
Lomar, Pedro Vieira Soares. Paths of Coffee Innovation in Brazil - Analysis of Possibilities with focus on the Zona da Mata Mineira. Rio de Janeiro, 2017. 43 p. Trabalho de Conclusão de Curso - Departamento de Administração. Pontifícia Universidade Católica do Rio de Janeiro.

This paper analyses the current landscape of coffee innovation in Brazil, focusing on the Consórcio de Pesquisa de Café, an arrangement of institutions that centralizes research, financing and technology transfer regarding this commodity. Also, it provides special attention to the situation in the Zona da Mata Mineira, one of Brazil's most important regions when it comes to coffee production. Lastly, it proposes policy shifts that could make coffee innovation more effective and value-creating, with more participation by organizations related to the industrial sector, local wholesaling and exporting companies.
\end{abstract}

Key words: Coffee, agribusiness, innovation, Minas Gerais, Zona da Mata. 


\section{Sumário}

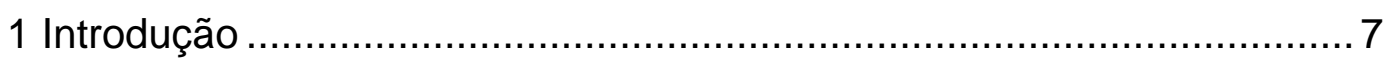

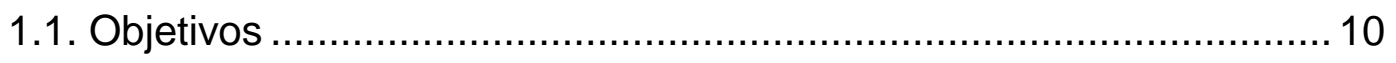

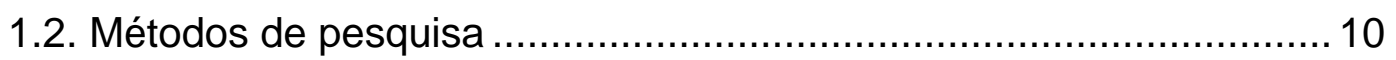

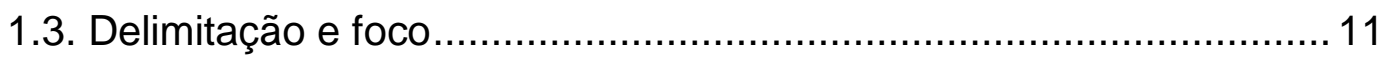

1.4. Justificativa e relevância .............................................................. 11

1.5. Organização do Trabalho ............................................................ 12

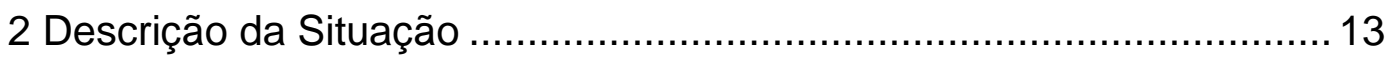

2.1. Inovação de Café no Brasil ........................................................... 13

2.1.1. Consórcio Brasileiro de Pesquisa e Desenvolvimento do Café -

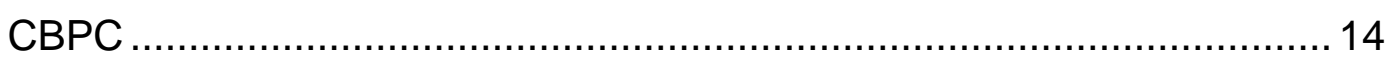

2.1.1.1. Pesquisa e Desenvolvimento ………………........................ 19

2.1.1.2. Transferência de Tecnologias ................................................ 19

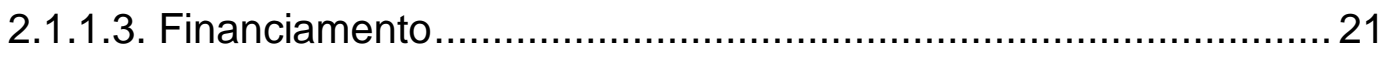

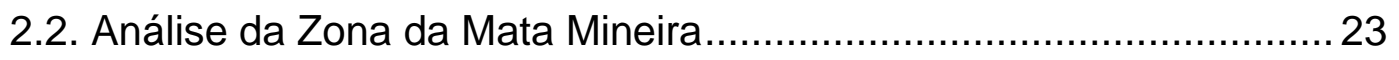

2.2.1. Inovação na Zona da Mata Mineira............................................... 24

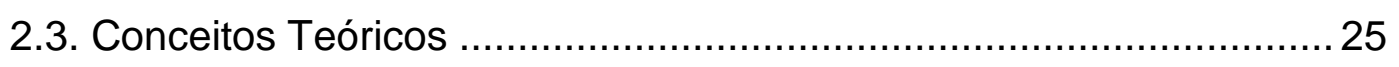

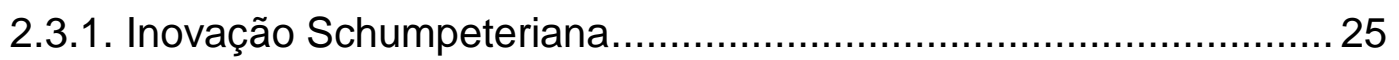

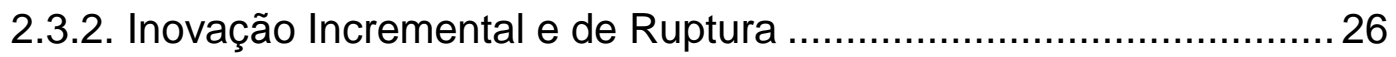

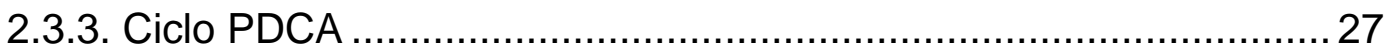

2.3.4. Importância da Análise Ambiente Organizacional ...........................29

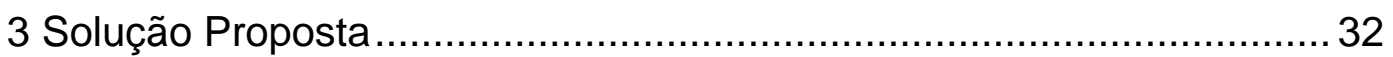

3.1. Situação atual ..................................... Erro! Indicador não definido.

3.2. Proposta de mudança ................................................................... 33

3.2.1. Pesquisa e Desenvolvimento .................................................... 33

3.2.2. Transferência de Tecnologia.................................................... 34

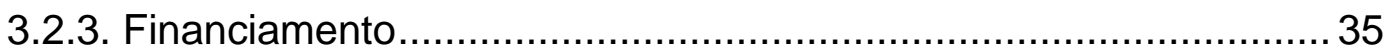

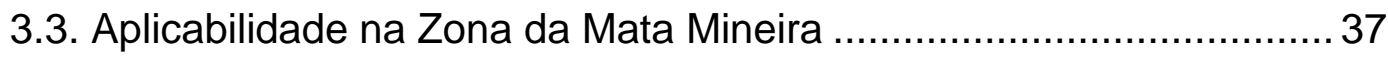

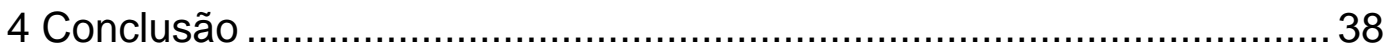




\section{Lista de figuras}

Figura 1 - Regiões produtoras de café separadas por nome (Brazilian

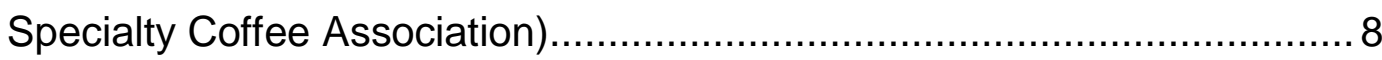

Figura 2 - Cadeia produtiva e de distribuição de Café ............................... 9

Figura 3 - Estrutura Geral do Sistema de Gestão do Consórcio - SGC.. 17

Figura 4 - Recursos disponibilizados pelo FUNCAFÉ entre 2000 e 2015

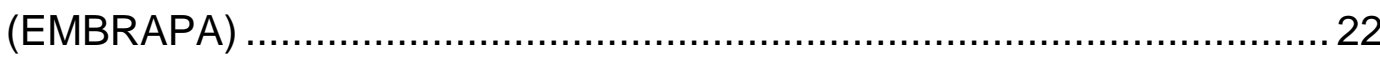

Figura 5 - Ciclo PDCA (Portal Administrador) .......................................28

Figura 6 - Tipos de ambiente em uma empresa (SOBRAL e PECI)........30

\section{Lista de Tabelas}

Tabela 1 - Demonstrativo Orçamentário e Financeiro do Consórcio Brasileiro de Pesquisa de Café - 2012 a 2014 ....................................... 42 


\section{Introdução}

A atividade cafeeira é um dos carros-chefes da economia brasileira, respondendo, em dezembro de 2016, por 9,8\% das exportações do país, um movimento de US\$ 600 milhões (Ministério da Agricultura, 2016). Na safra registrada entre 2015 e 2016, foram colhidas 43,2 milhões de sacas de 60 quilogramas, volume que qualifica o país como maior produtor e exportador de café em grão do planeta, com $30 \%$ de toda a produção mundial, quase o dobro do segundo maior, o Vietnã (International Coffee Organization, 2016). Além disso, o Brasil está consolidado como o segundo maior consumidor mundial de café, com o mercado interno comprando 20,5 milhões de sacas em 2015, seguindo um movimento de alta que já dura 15 anos (Associação Brasileira de Indústrias de Café).

Em relação a outros países, porém, a economia brasileira está atrasada em termos de aproveitamento do potencial do setor cafeeiro. Exporta-se quase que somente café em grãos, deixando para países do Hemisfério Norte todo o potencial de processamento de café para exportação de produto final. A Alemanha é o maior exportador de café do mundo em termos de receita, sem produzir um único grão (THIEMANN, 2012), e o setor cafeeiro do Brasil deveria aprender com esse exemplo como agregar valor ao produto.

Além disso, o café produzido no Brasil não é em geral considerado como de qualidade. Nesse sentido, o marketing e a certificação dos cafés é bastante importante - um exemplo é o selo Juan Valdez, fornecido por organizações de produtores na Colômbia, que já possui um histórico no mercado associando o café desse país à ideia de qualidade excepcional e cuidado com as condições dos produtores, o que gera um aumento de vendas e um grande reconhecimento internacional (PENDERGRAST; 1999, p. 260). 
O setor no Brasil atinge elementos diversos, com cadeias econômicas ramificadas e impacto em diferentes regiões. Oito estados, distribuídos em quatro das cinco regiões do país, produzem o grão em quantidades relevantes. Desses, o produto é de particular importância em Minas Gerais, onde $50 \%$ do café brasileiro é produzido. O estado possui 4 regiões de produção - Sul de Minas, Cerrado de Minas, Zona da Mata e Cerrados de Minas (Figura 1) - que cobrem a maior parte de sua área, e o café é hoje o produto agrícola mais forte da região, respondendo por $14 \%$ de suas exportações totais, de acordo com a Brazilian Specialty Coffee Association.

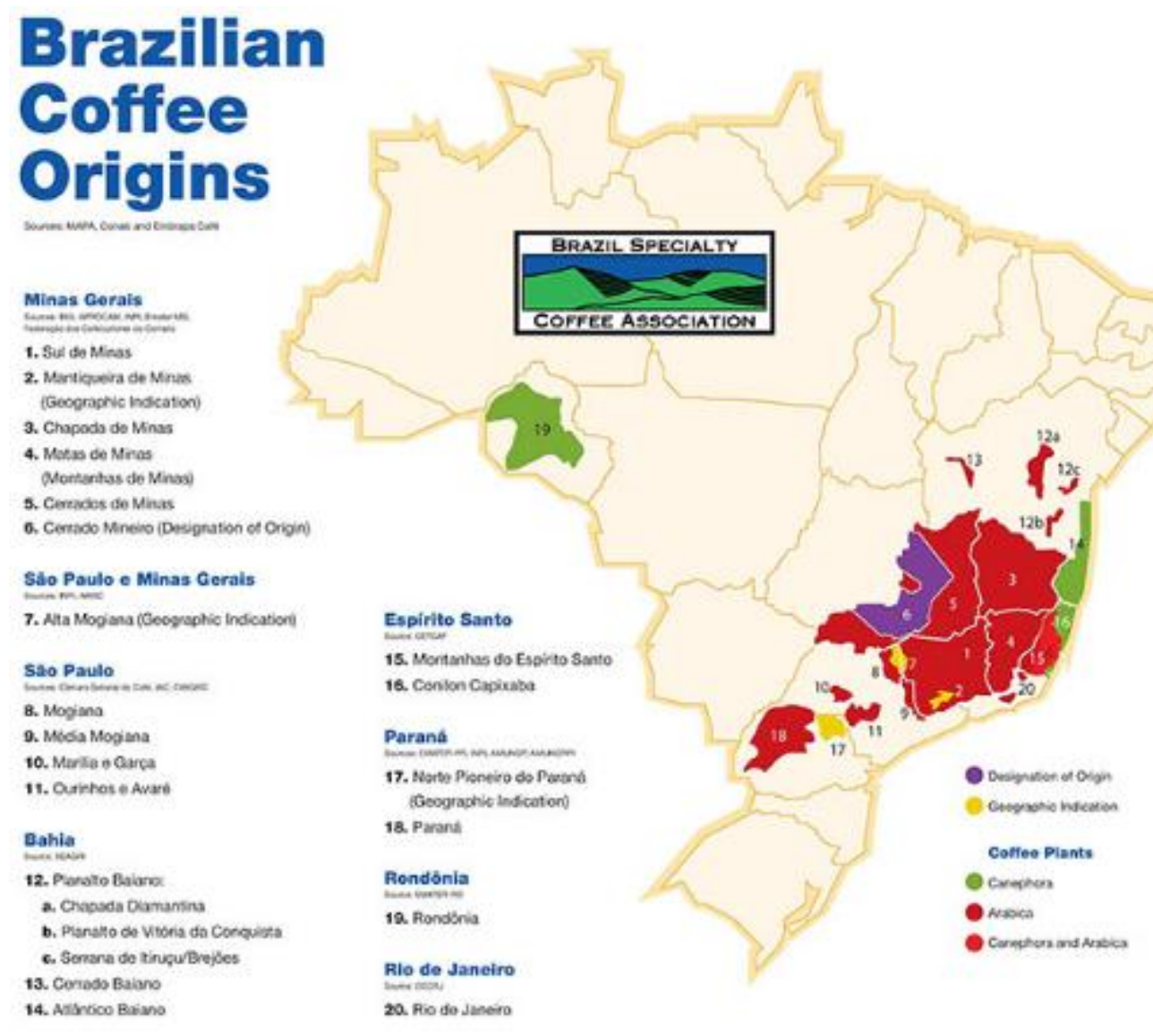

Figura 1 - Regiões produtoras de café separadas por nome (Brazilian Specialty Coffee Association)

O mercado cafeeiro possui importantes stakeholders que acompanham o processo desde a colheita do café na lavoura até o seu consumo dentro ou fora do Brasil. Essa organização produtiva é delineada na Figura 2. A produção do grão é 
pulverizada, com poucos produtores grandes e dispersão de áreas produtivas, o que torna essencial o papel de outros elementos para que o caminho do café até a mesa seja percorrido. Um dos principais deles é o comerciante de café, que compra lotes pequenos e dispersos de diferentes produtores rurais, reúne-os e revende para indústrias de torrefação de café no mercado interno ou para exportadoras no mercado externo. Apesar de algumas exportadoras estarem se aproximando do produtor para tentar a compra direta, em uma tentativa de eliminar um elemento da cadeia e aumentar o lucro, o sistema já está consolidado assim e o comerciante atacadista é o elemento de ligação entre a lavoura e a indústria de transformação, seja ela interna ou externa. Além disso, corretores, representantes de indústrias e agências relacionadas a café ajudam a tornar cidades específicas em polos do mercado de café. Dentre as principais destacam-se Manhuaçu (MG) e Franca (SP). Após a compra no mercado externo por um importador, o café é vendido para grandes consumidores estrangeiros (ex: redes de cafeterias) ou para indústrias de torrefação estrangeiras. Apesar de algumas indústrias e consumidores internacionais estarem tentando a compra direta com produtores, existe muita dificuldade devido à falta de escala, a exemplo das dificuldades encontradas por exportadores.

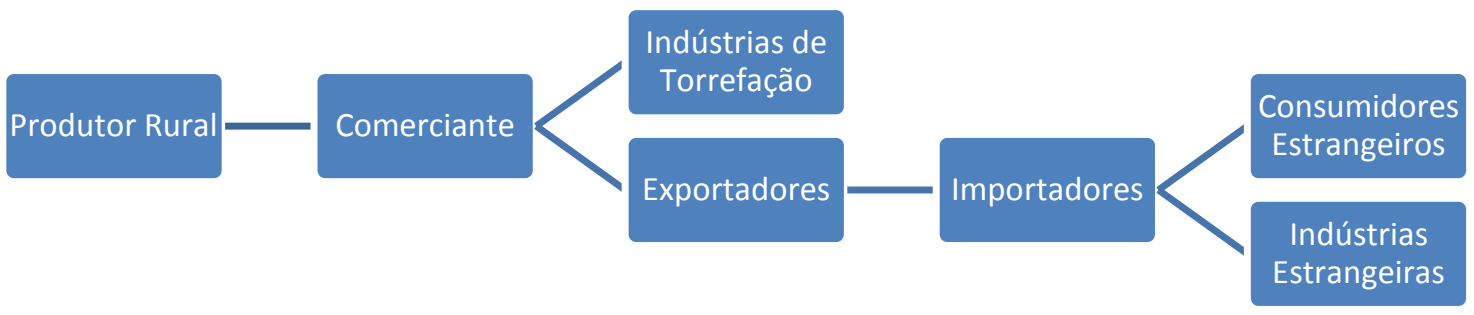

Figura 2 - Cadeia produtiva e de distribuição de Café. 
Aumentar a quantidade de café produzido e a qualidade média dos grãos é uma necessidade para a melhoria dos preços obtidos por produtores rurais no ato da venda de café. Para ajudar o produtor nessas tarefas, existem instituições e agências governamentais que contribuem para o desenvolvimento de inovações voltadas para a produção de café, além de sua divulgação e transferência.

Tendo em vista a necessidade de se melhorar a qualidade do café produzido, deve-se levar em conta o aumento da atenção internacional para os chamados cafés especiais. Enquanto grande parte dos cafés é vendida usando como referência o valor dessa commodity na bolsa de Nova York, o café especial não segue a mesma lógica de mercado. A precificação de cada lote de café especial é feita separadamente, com base na avaliação do produto por provadores certificados que graduam o café em processos de prova similares aos de classificação de vinhos, com notas de 0 a 100, sendo 80 o mínimo necessário para se obter uma certificação. Um produtor que atinge esse nível possui um nível de geração de riqueza bastante superior ao dos demais.

\subsection{Objetivos}

Este trabalho tem como objetivo principal propor mudanças para o sistema atual de inovação de café no Brasil, a partir de uma análise do setor, identificando de que formas essas alterações contribuem para o melhor desenvolvimento econômico na região da Zona da Mata Mineira.

\subsection{Métodos de pesquisa}

Segundo Tozoni-Reis, "metodologia é um caminho a ser trilhado pelo pesquisador no processo de produção de conhecimentos sobre a realidade que se busca conhecer". Além disso, "pode ser vista como um conjunto de procedimentos que não se resumem a técnicas e instrumentos de pesquisa, mas as incluem" (TOZONI- 
REIS, p. 23). Nesse processo, as reflexões teóricas devem ter importância fundamental.

Foi aqui realizada uma pesquisa bibliográfica sobre o tema da inovação do café no Brasil, tendo sido encontrados estudos no portal Biblioteca do Café, que reúne em um website grande parte da pesquisa relacionada a café feita pela Universidade Federal de Viçosa - UFV e Universidade Federal de Lavras - UFLA. Outros trabalhos utilizados incluem artigos de teóricos de inovação (Schumpeter e Christensen), livros de administração e textos governamentais

Além disso, foi feita uma pesquisa de campo por meio de entrevistas informais com produtores rurais da região da Zona da Mata Mineira, contribuindo com impressões sobre o mercado de café local e sobre ações de inovação. Foi realizada também uma entrevista semiestruturada através de e-mail com um pesquisadormembro do arranjo institucional brasileiro de inovação em café.

Finalmente, parte do trabalho partiu de observações pessoais do autor, que trabalha no setor em uma empresa de comércio atacadista de café na Zona da Mata Mineira.

\subsection{Delimitação e foco}

O estudo analisa o contexto da inovação voltada para café no Brasil, com foco na atuação do Consórcio Pesquisa Café. Será dada uma atenção especial em como essa inovação pode influenciar a região da Zona da Mata Mineira.

\subsection{Justificativa e relevância}

O estudo é relevante por analisar a inovação em um dos pilares da economia brasileira, visto que o café é um gerador de riqueza e uma das commodities agrícolas mais importantes do mundo.

No contexto específico da Zona da Mata Mineira, dada a condição do café como sua principal atividade produtiva, espera-se contribuir para o setor com análises e propostas que gerem ganhos materiais para produtores rurais e demais participantes do setor cafeeiro na região. 
Do ponto de vista acadêmico, espera-se contribuir com referências para futuros estudos sobre inovação no mercado de café do Brasil.

\subsection{Organização do Trabalho}

Essa parte introdutória contém, além de uma contextualização do setor de produção de café no Brasil, a definição dos objetivos do trabalho, complementada pela descrição dos métodos de pesquisa utilizados, a delimitação e foco do trabalho e apreciação de sua relevância.

O segundo capítulo abrange uma descrição do cenário de inovação de café no Brasil, incluindo uma caracterização do Consórcio Brasileiro de Pesquisa de Café, com foco nas atividades de pesquisa e desenvolvimento, transferência de tecnologias e financiamento. Em seguida, apresenta a Zona da Mata Mineira no cenário de café. É colocado também um referencial teórico com definições técnicas de inovação.

No capítulo 3, é proposta uma solução para as dificuldades encontradas pelo modelo atual de inovação de café no Brasil, incluindo sugestões de novas políticas que aumentariam a geração de riqueza e melhorariam a eficiência do setor. A aplicabilidade dessas ações é analisada também em uma seção separada dentro do contexto da Zona da Mata Mineira.

Por fim, a conclusão resume o trabalho realizado, avaliando o cumprimento de seu objetivo. As ações propostas são resumidas e são abertas possibilidades de novos estudos futuros. 


\section{Descrição da Situação}

É importante traçar um panorama tanto do universo de inovação de café no Brasil como das particularidades da região da Zona da Mata. Este capitulo procura explicar a situação atual, pavimentando a discussão para propor mudanças.

\subsection{Inovação de Café no Brasil}

Ao se descrever a inovação em café no Brasil, deve-se fazer a distinção entre a inovação no setor primário e no setor secundário. Apesar de todo o foco ser voltado para a produção da matéria prima, existem esforços pontuais no sentido de melhorar processos de torrefação e moagem, bases da produção do café como produto final na forma como é conhecido e vendido. Aqui, é importante ressaltar que a transformação do café in natura em produto final para consumo representa uma enorme adição de valor na mercadoria, influenciando diretamente sua qualidade. Com isso, mesmo sendo o maior exportador de café em grãos do mundo, o Brasil precisa se esforçar para fazer frente, por exemplo, à Alemanha, que, como visto na seção 1, é o maior exportador mundial de café em termos de faturamento, justamente por comprar a mercadoria e processá-la atingindo bons níveis de qualidade, distribuindo para outros países de primeiro mundo.

No setor primário, existem associações ligadas à indústria de café que promovem a inovação, muitas vezes incentivando a produção de cafés de qualidade superior para certificação e promovendo concursos de qualidade. A Associação Brasileira da Indústria de Café - ABIC possui recomendações técnicas a serem seguidas por produtores para a certificação de café.

Já no setor secundário, um exemplo recente de avanço feito foi uma pesquisa da Universidade de São Paulo - USP coordenada com a ABIC - Associação Brasileira de Indústrias de Café, que busca entender o processo de torrefação em diferentes 
produtores para propor técnicas que possam melhorar a qualidade e a percepção sobre o produto final (SAES, 2012). Ainda assim, esforços nesse sentido são pontuais e descentralizados. Mesmo que se possa argumentar que a localização geográfica do Brasil atrapalha a distribuição e venda global do produto final, os caminhos da inovação em café no Brasil passam pela valorização da produção de cafés para consumo, que, por sua vez, necessita de investimentos mais pesados em tecnologia (CECAFÉ, 2010).

Além de iniciativas como a acima mencionada, a Inovação de café no Brasil é marcada pela formação de um consórcio de pesquisa que engloba diversas instituições focadas no tema, com investimentos exclusivos para o setor primário de produção de café em grãos, o Consórcio Brasileiro de Pesquisa e Desenvolvimento do Café.

\subsubsection{Consórcio Brasileiro de Pesquisa e Desenvolvimento do Café - CBPC}

Existem alguns exemplos de organizações na agricultura que integram a inovação de determinados setores produtivos - destacam-se a Rede Genolyptus, criada para o desenvolvimento de pesquisas sobre o eucalipto, e o Fundecitrus, associação de prestação de serviços e financiamento de pesquisa com cítricos (MENDES; 2009, p. 8), na área do café, existe o Consórcio Brasileiro de Pesquisa e Desenvolvimento do Café - CBPB.

A coordenação das diretrizes brasileiras relacionadas a café foi mediada pelo Instituto Brasileiro de Café - IBC desde sua fundação, em 1956, até os anos 80. Autarquia federal vinculada ao Ministério da Indústria, Comércio e Turismo - MICT, o Instituto costumava sofrer duras críticas relacionadas à corrupção e à falta de uma integração clara que gerasse frutos e benefícios para o produtor de café. Não foram poucas as críticas sofridas por o órgão não promover a inovação e o marketing, 
apesar de já ter chegado, por exemplo, a patrocinar a seleção brasileira de futebol entre 1979 e 1983. Sem maiores explicações, o Instituto foi extinto em 1990.

Após isso, a cadeia produtiva de café ficou seis anos sem apoio institucional para seu desenvolvimento, até a assinatura, em 1996, de uma série de iniciativas governamentais voltadas à organização do setor, como a criação de um Programa Nacional de Desenvolvimento do Café - PNPD, pelo MCIT, para o desenvolvimento de ações de P\&D e transferência de tecnologias de café, e a criação do Conselho Deliberativo de Política de Café pelo Governo Federal - CDPC para discutir o setor de forma estratégica, tendo uma função semelhante à que o IBC tinha originalmente (MENDES; 2009, p. 130).

Nesse contexto, o Consórcio Brasileiro de Pesquisa e Desenvolvimento de Café - CBPC surgiu representando o braço científico do CDPC, para discutir a realização do PNPD. Nessa nova organização, o intuito foi integrar todos os stakeholders relacionados à produção de conhecimento, como governo, institutos de pesquisa e universidades. O termo de constituição do Consórcio possui a assinatura de 10 órgãos fundadores: Empresa Baiana de Desenvolvimento Agrícola - EBDA, Empresa Brasileira de Pesquisa Agropecuária - EMBRAPA, Empresa de Pesquisa Agropecuária de Minas Gerais - EPAMIG, Instituto Capixaba de Pesquisa - INCAPER, Assistência Técnica e Extensão Rural, Instituto Agronômico de São Paulo - IAC, Instituto Agronômico do Paraná - IAPAR, Empresa de Pesquisa Agropecuária do Estado do Rio de Janeiro - PESAGRO-RJ, Ministério da Agricultura, Universidade Federal de Viçosa - UFV e Universidade Federal de Lavras - UFLA (MENDES; 2009, p.132). A cláusula primeira do ato de constituição define como objetivo principal a "conjugação de recursos humanos, físicos, financeiros e materiais das instituições signatárias, e a captação de recursos adicionais para o desenvolvimento do Programa Nacional de Desenvolvimento do Café (CBP\&D/Café; 1997, p. 3). O texto constitutivo 
define ainda que a organização não é uma pessoa jurídica, e que a sede seria a mesma da Consorciada Administradora, ocupação que cabe à EMBRAPA.

Além disso, a cláusula quarta considera que não poderão entrar no Consórcio outras empresas sem que haja aprovação prévia de um Conselho Diretor. Instituições "públicas e privadas, que tenham objetivos coerentes com os executados por este Consórcio, que desenvolvam, incentivem, promovam ou financiem estudos, pesquisas, tecnologias e informações sobre o negócio café, poderão associar-se, mediante Termo de Adesão" (CBP\&D/Café; 1997, p. 4).

É interessante avaliar que existem basicamente dois tipos de instituições fundadoras: universidades (UFLA e UFV) e empresas públicas estaduais e federais (caso da EMBRAPA) de apoio à agricultura. Todas as ações de P\&D e transferência de tecnologia são coordenadas pela EMBRAPA, que criou uma ramificação específica para o setor, a EMBRAPA Café.

Em termos de estrutura organizacional (Figura 2), as instituições consorciadas atuam na parte operacional do Consórcio, porém comunicam diretamente com o comitê de gestão estratégica, que define as diretrizes a serem estudadas (EMBRAPA; 2013, p. 13). Além disso, a decisão sobre os membros desse comitê (que inclui conselho assessor e conselho diretor do consórcio) cabe às instituições fundadoras. Logo, o modelo é retroalimentado pelas mesmas pessoas que o executam. 


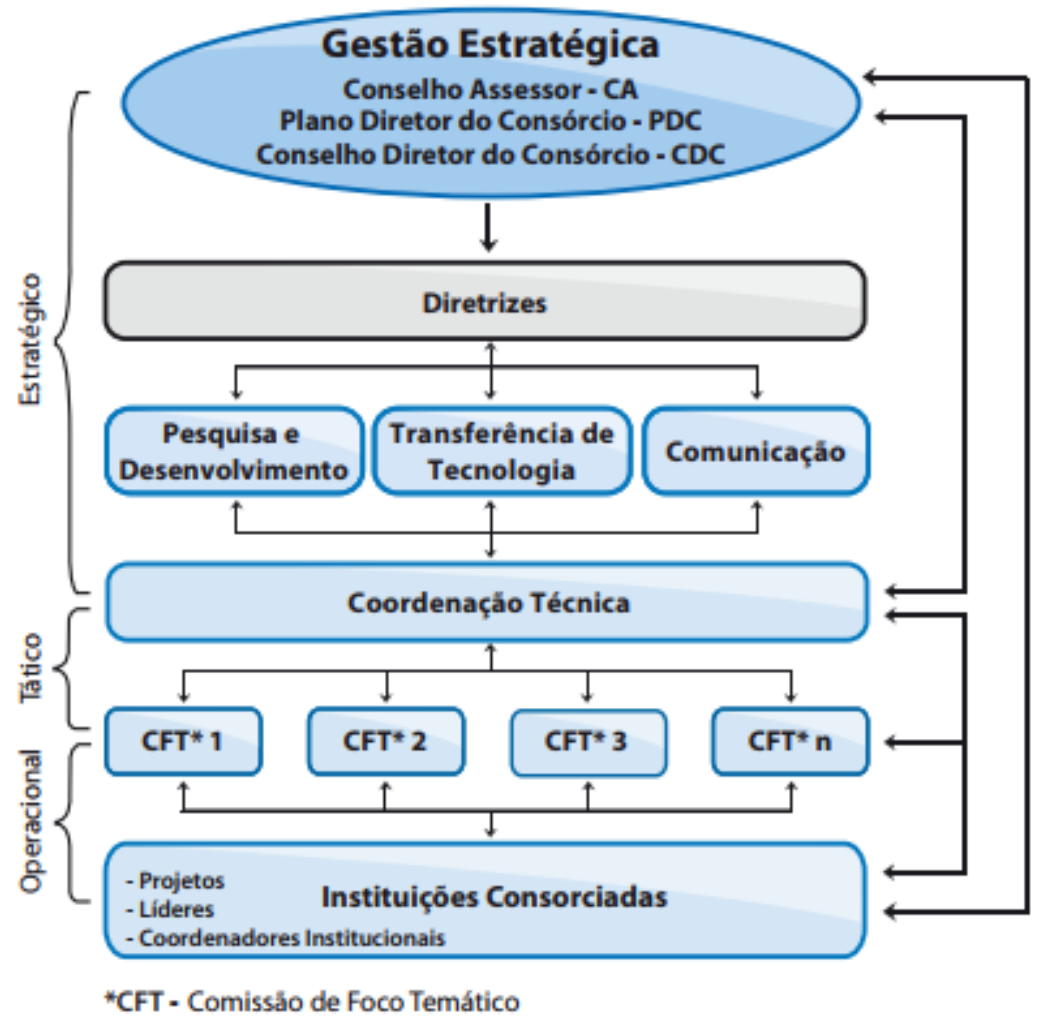

Figura 3 - Estrutura Geral do Sistema de Gestão do Consórcio - SGC

A formação do CBPC foi importante para o setor cafeeiro e representou uma novidade, considerando-se que houve, pela primeira vez, um esforço no sentido de organizar pesquisas na área. Há de se observar que o fim do IBC desestruturou políticas nacionais de produção e comércio de café, porém não foi prejudicial para a pesquisa e desenvolvimento, visto que não havia nenhum comprometimento do IBC com essas atividades.

O papel das organizações privadas na articulação do CBPC é limitado e ocorre principalmente pela participação de organizações representantes de classe empresariais, dentre elas a Associação Brasileira da Indústria do Café - Abic e o Conselho dos Exportadores de Café - CECAFÉ, principalmente no que tange à apresentação dos tópicos demandados pelos produtores para pesquisa e da autorização de programas de desenvolvimento. O financiamento de pesquisa 
raramente é feito por instituições privadas e há pouco alinhamento entre empresas, produtores e os órgãos de pesquisa (MENDES; 2009, p. 139).

Como discutido, o Consórcio tem como objetivo coordenar e regular a propriedade intelectual e articular os agentes internamente (MENDES; 2009, p. 145). Cabe destacar suas funções principais dentro dessa coordenação. No que tange ao objetivo do Consórcio - a melhoria dos níveis de inovação e utilização pela cadeia produtiva de café no Brasil - pode-se separar em duas as funções do CDPC: Pesquisa e Desenvolvimento e Transferência de Tecnologias. Quanto a essa última, é de vital importância ressaltar a dificuldade que instituições de pesquisa brasileira têm em colocar em prática as inovações produzidas, o que fica visível ao se comparar o baixo número de patentes produzidas em comparação com o razoável número de artigos científicos escritos (MELO; 2009, 11). Há uma terceira função que, apesar de não se tratar do objetivo fim, é de suma importância para seu atingimento, que é o financiamento dos diversos órgãos e iniciativas de inovação.

Pode-se, portanto, considerar três principais funções do CPDC:

1- Investir em pesquisas que atendam às necessidades dos agentes da cadeia produtiva de café;

2- Divulgar e acompanhe a implementação das inovações nos diferentes atores dessa cadeia;

3- Articular o financiamento das iniciativas de inovação.

Segue-se uma discussão dos processos de pesquisa e desenvolvimento, de transferência de tecnologias e de financiamento de pesquisa e desenvolvimento, bem como qual é o papel das organizações privadas no seu direcionamento. 


\subsubsection{Pesquisa e Desenvolvimento}

O CDPC usa um modelo participativo, com a coordenação centralizada e execução descentralizada. Assim, qualquer uma das organizações participantes pode escolher temas para pesquisa de acordo com as próprias necessidades. Há, porém, um encaminhamento por meio do Programa Café, uma diretriz organizada com base em 12 núcleos de referência amplos identificados como demandados pelo setor (MENDES; 2009, p. 142), que incluem biotecnologia aplicada ao café e manejo de lavoura. O Consórcio costuma ser constituído apenas como uma soma de projetos dispersos realizados em diferentes áreas - atuando mais como um coordenador e sem conseguir cumprir o papel de integrador. Isso pode ter suas raízes nas características regionais do café, com a área geográfica influenciando variáveis climáticas, o que altera estudos ligados à produção agrícola. Nota-se, porém, que tal integração poderia ser importante para o desenvolvimento de inovações mais complexas, como pesquisas ligadas à biotecnologia. Além disso, percebe-se um desalinhamento grande entre a agenda de pesquisa e as reais necessidades do setor produtivo, consequência da falta de um sistema que aproxime as partes, em vez de isolá-las (MENDES; 2009, p. 145).

\subsubsection{Transferência de Tecnologias}

Uma das maiores vulnerabilidades do CDPC encontra-se na interação para a transferência das tecnologias produzidas no arranjo (MENDES; 2009, p. 146). Os únicos itens que não receberam nota positiva em pesquisa realizada no Paraná com agentes da cadeia produtiva e de inovação de café - que inclui produtores, comerciantes e exportadores, bem como pesquisadores e pessoas ligadas à universidade - foram a divulgação dos resultados e técnicas pesquisadas e a 
participação dos agentes do setor na discussão sobre o que deveria ser pesquisado a seguir. Segundo B.D., um pesquisador da Embrapa Café entrevistado, esses problemas de consistência não existem, e o estabelecimento das políticas do CPDC visa o desenvolvimento do agronegócio do café como um todo, sem benefício de partes específicas da cadeia. Nota-se, porém, um desalinhamento entre esse discurso e a percepção dos agentes do setor, que se sentem ainda desassistidos e pouco influentes nessas decisões (MENDES; 2009, p. 147).

Existem diversas ações de transferência de tecnologia que podem ser colocadas em prática, como disponibilização de sementes para agricultores (CORNÉLIO; 2013) e eventos como dias de campo em fazendas (ROMANIELLO; 2011). As ações, porém, não são acompanhadas corretamente, o que é considerado um fator crítico a ser solucionado, fruto de problemas na própria estrutura descentralizada do CDPC (MENDES; 2009, 147). A situação é menos dramática em estados que já possuem empresas públicas de extensão rural que atuam em conjunto com órgãos de pesquisa, o melhor exemplo sendo a ação conjunta da Empresa de Pesquisa Agropecuária de Minas Gerais - EPAMIG com a Empresa de Assistência Técnica e Extensão Rural - EMATER em Minas Gerais. Contudo, a realidade está longe do ideal (MENDES; 2009, p. 147) - calcula-se que, entre 2004 e 2007, apenas 130 mil pessoas ligadas ao agronegócio do café tenham sido atingidas de alguma forma, um resultado tímido se for considerado que o setor é responsável pela criação de sete milhões de empregos diretos e indiretos no Brasil.

Ações de transferência coordenadas pelo Consórcio, muitas vezes, incluem iniciativas que não tentam chegar ao produtor, como a criação de um parque tecnológico na cidade de Varginha, em que há exposição da tecnologia produzida, porém pouco acessível e sem considerar diferenças culturais, incluindo a baixa instrução média dos agentes do sistema (MENDES; 2009, p. 147). 


\subsubsection{Financiamento}

O ato formativo do Consórcio define que "o CDPC diligenciará, em conjunto e por meio de cada instituição consorciada, perante as fontes ordinárias e extraordinárias, públicas ou privadas, de financiamento de pesquisa e desenvolvimento agroindustrial, sócio econômicas e mercadológicas, em geral, e cafeeira em particular, para a captação de recursos, com o fito de ampliar as disponibilidades financeiras do Consórcio ou de cada instituição consorciada, para a consecução dos objetivos propostos" (CBP\&D/Café; 1997, p. 5). Portanto, o Consórcio atua mais como uma organização de controle: todos os filiados prestam contas e designam uso para os recursos. No entanto, ao menos em princípio, cada órgão é responsável por buscar suas próprias fontes de financiamento.

Dentre todas diversas fontes de financiamento que podem ser procuradas pelos órgãos (empresas privadas, doadores particulares, fundos de gestão), uma se destaca como sendo a maior fonte de recursos: o Fundo de Defesa da Economia Cafeeira - FUNCAFÉ, recurso Federal fornecido pelo Ministério da Agricultura com aportes diretos dentro das Leis Orçamentárias Anuais - LOAs das organizações do Consórcio. A totalidade dos recursos é investida diretamente na EMBRAPA, que possui a função de repassá-los para outros membros do Consórcio. No entanto, muitas vezes parte desses recursos é transferida para uma reserva de contingência e não é destinada a investimento.

A Figura 3 mostra que o volume de dinheiro disponibilizado pelo FUNCAFÉ em 2015 foi baixo em comparação com o disponibilizado nos dois primeiros anos do Século XXI (EMBRAPA; 2015, p. 75). Além disso, existe um claro movimento de decadência do fundo desde 2010, que vem angariando desde então cada vez menos recursos. 
De acordo com a própria EMBRAPA, os recursos não vêm sendo "suficientes para arcar com o desenvolvimento dos projetos aprovados e dos convênios para celebrar parcerias de pesquisa e transferência de tecnologia" (EMBRAPA; 2015, p. 75). Em 2012, por exemplo, $\mathrm{R} \$ 12$ milhões foram aprovados pelo fundo, mas apenas $R \$ 8$ milhões foram investidos, recursos que foram insuficientes para promover a ampliação do CPDC, conforme relatório da EMBRAPA (EMBRAPA; 2015, p. 76).

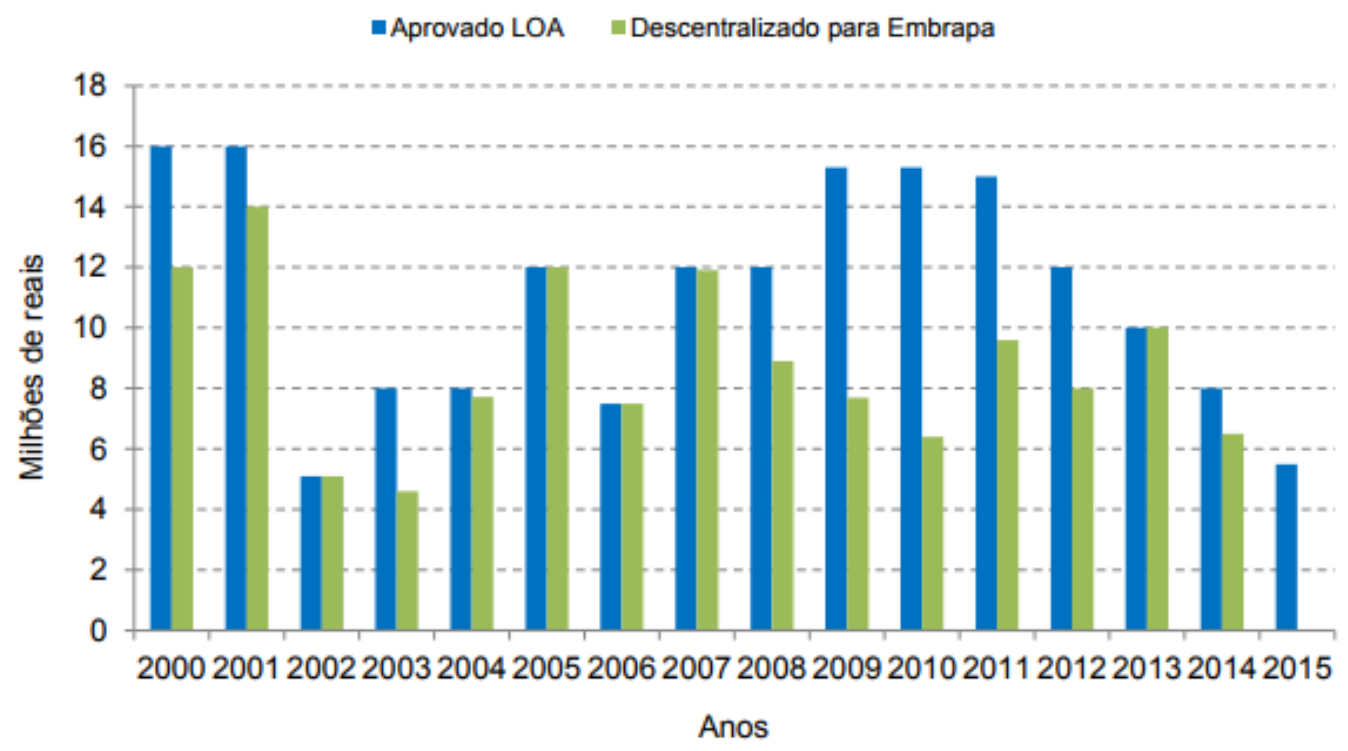

Figura 4 - Recursos disponibilizados pelo FUNCAFÉ entre 2000 e 2015 (EMBRAPA)

Os dados financeiros do FUNCAFÉ, entre 2012 e 2014, estão disponíveis no Anexo 1. Com ele, pode-se constatar que a maior parte dos recursos alocados está nas instituições estaduais de fomento à agricultura (por exemplo, em 2014, 50\% dos recursos executados foram para esses órgãos). As duas universidades conveniadas, UFV e UFLA, recebem poucos recursos em comparação a essas instituições (R\$ 216 mil para cada uma em 2014, menos de $10 \%$ do total repassado para a EMBRAPA).

Pode-se identificar, com isso, uma maior preocupação com a transferência de tecnologia (dado que as instituições estaduais de fomento à agricultura são a priori as 
responsáveis por essa função) do que com a produção de novos conhecimentos (função das universidades).

\subsection{Análise da Zona da Mata Mineira}

A Zona da Mata Mineira é uma das quatro áreas produtivas de café no estado de Minas Gerais e, juntamente do Sul de Minas e do Cerrado Mineiro, uma das três com certificado de origem. Contudo, em comparação com essas, o café da região ainda é considerado de qualidade inferior.

Essa percepção, apesar de ser baseada em hábitos do mercado, possui fundamento: em comparação com o Sul de Minas, por exemplo, a Zona da Mata é uma região com produtores rurais pouco instruídos que não extraem do solo todo o seu potencial produtivo - tanto em termos de qualidade como de quantidade. Comparando-se dois dos principais centros de comércio de café em Minas Gerais, ambos representantes centrais de suas áreas - Varginha no Sul de Minas e Manhuaçu na Zona da Mata Mineira - percebe-se uma distância muito grande no número de habitantes com ensino superior completo (IBGE, 2010). Em Manhuaçu, apenas 3,8\% da população possui esse nível de instrução (3.379 pessoas), contra 9,4\% em Varginha (12.573 pessoas).

Esse fator faz com que o potencial da área não seja totalmente aproveitado. Coroada pelo Pico da Bandeira (terceira montanha mais alta do Brasil), a área possui as condições climáticas ambientais consideradas ideais para a atividade. $\mathrm{O}$ fator altitude, juntamente com a exposição das lavouras ao sol e genética das mudas, é essencial na determinação de uma região como de potencial para a produção de cafés especiais (SILVEIRA; 2015, 25). 
Além disso, existe a percepção geral de que a região, se bem cuidada e trabalhada, teria potencial para aumentar sua participação em volume no total de café produzido no Brasil, que em 2006 foi de apenas 11,23\% (PIRES, 2003).

\subsubsection{Inovação na Zona da Mata Mineira}

Pode-se, inicialmente, falar de fazendas que vêm melhorando a qualidade de produção com novas técnicas aprendidas, como é o caso da Fazenda Lacerda, na cidade capixaba de Águia Branca (fronteira com Minas Gerais). Essa fazenda chegou a passar por dificuldades financeiras nos últimos anos e conseguiu evoluir até chegar à condição de ter seu café considerado como um dos melhores do Brasil. Ainda que para alcançar essa condição ela tenha se valido da transferência de tecnologias de empresas como a EMATER, que faz parte do consórcio que será descrito, é importante valorizar o esforço individual de produtores em aplicar as novas tecnologias de produção e acreditar no resultado delas. Isso é relevante quando se fala de um setor tradicional da Economia Brasileira caracterizado, principalmente na região da Zona da Mata, por produtores de pequeno porte (a Fazenda Lacerda, por exemplo, é essencialmente familiar), que muitas vezes tendem a se valer das mesmas técnicas e sistemas produtivos aplicados pelos antepassados.

No passado recente, outras fazendas da região vêm produzindo cafés de qualidade superior dentro do grupo dos chamados cafés especiais, que mesmo sem a obtenção de prêmios, como no caso da Fazenda Lacerda, podem valorizar a mercadoria do produtor em até 150\% (BONATO, 2015).

Quanto ao setor secundário, percebe-se que a região carece da presença de indústrias de café mais desenvolvidas. Das 100 maiores indústrias brasileiras de café, apenas uma, a Café Toko, está localizada na região (cidade de Juiz de Fora), o que, Isso, por si só, dificulta a introdução de qualquer inovação na parte industrial do café na região, tornando desnecessário mencionar os fatores referentes à falta de apoio 
nesse sentido em âmbito nacional. A inovação no setor secundário de café é mais viável em regiões produtoras com maior concentração de indústrias de torrefação e moagem, caso das regiões Mogiana (centro industrial em Mogi das Cruzes) e Sul de Minas (centro industrial em Varginha).

\subsection{Conceitos Teóricos}

O referencial teórico para explicar e analisar o modelo de inovação em café deve levar em conta aspectos de administração para buscar a melhor forma de gerenciar um sistema complexo que envolve um número elevado de stakeholders e órgãos nele atuando diretamente.

Além disso, existem aspectos referentes ao estudo de inovação que devem ser levados em conta na hora de traçar objetivos e consequências de uma gestão em âmbito nacional.

Os aspectos teóricos de inovação mais relevantes para este trabalho e sua relação com o assunto estudado são sintetizados a seguir.

\subsubsection{Inovação Schumpeteriana}

Ao longo do século XXI, a inovação vem sendo discutida para se buscar o entendimento do seu papel no desenvolvimento econômico de países e empresas. Durante muito tempo, o conceito de inovação sempre foi muito ligado apenas à ideia de invenção e de descobertas científicas (RUTTAN; 1959, p. 597). O marco inicial do estudo dessa área de interesse como um fator de impacto na vida das sociedades vem de Joseph Schumpeter e seus estudos na primeira metade do século XX. Ao propor uma teoria de desenvolvimento econômico que considerava inovação científica, acesso a crédito e maximização de lucros como os três pilares do capitalismo moderno, ele foi pioneiro em diferenciar o conceito de inovação: 
“Inovação é possível sem qualquer coisa que possa ser identificada como invenção, e invenção não necessariamente induz inovação, sendo que não produz, se isolada, qualquer efeito econômico" (SCHUMPETER; 1939, p. 80).

Schumpeter argumenta também que o processo que ocasiona a inovação é diferente daquele que promove a invenção, tanto economicamente quanto socialmente. Mais do que definir a inovação pelo que ela não é, Schumpeter a descreve em termos de uma mudança na forma de produção:

"Vamos definir inovação como simplesmente o estabelecimento de uma nova função produtiva. Isso cobre tanto o caso de uma nova commodity como os casos de novas organizações, fusões ou da abertura de novos mercados" (SCHUMPETER; 1939, p 84).

Assim sendo, quando se fala em inovação em café - ou em qualquer outro setor produtivo - não se deve impor a necessidade de invenções revolucionárias para se obter um resultado econômico positivo para produtores e comerciantes, e sim valorizar quaisquer medidas ou ações que tenham como consequência o melhor aproveitamento econômico por parte desses atores e a melhoria das condições de competição do mercado brasileiro de café frente aos concorrentes globais.

\subsubsection{Inovação Incremental e de Ruptura}

Quando se fala em inovação muitas vezes pode se ter a noção de que esse termo apenas engloba mudanças abruptas que geram novos mercados e criam um grande diferencial, perante as demais, para a empresa que a conquista. Um importante aspecto da inovação, porém, que não pode ser subestimado, é a inovação incremental, pela qual uma série de pequenos ajustes e melhoria em um produto, linha de produção ou processo, pode ajudar a manter e até a melhorar a posição competitiva da organização ao longo do tempo. 
Em se falando de produção de café, muitas vezes o foco é um sistema de inovação dirigido ao produtor rural, um modelo pulverizado que busca melhorar a vida de famílias com base no ensino de novas técnicas agrícolas que poderão ajudar a alcançar esse objetivo, proporcionando, por exemplo, uma maior produtividade ou um melhor nível médio de qualidade de café, com vistas a uma maior rentabilidade. Além disso, técnicas administrativas básicas, como controle de custos, poderiam, se passadas para os produtores com o devido acompanhamento, gerar uma melhoria nas condições de troca dessa classe.

O contraponto à inovação incremental é a inovação de ruptura, em que a descoberta de novas tecnologias e métodos cria novos mercados e torna produtos antigos obsoletos. De acordo com Christensen e Bower, a inovação de ruptura vem com a criação de tecnologias que, a princípio, não são valoradas pelos consumidores, mas que, se seguidas de uma mudança abrupta nas demandas desses, podem passar a ter a preferência dos clientes (CHRISTENSEN; 1995, p. 3).

Inovações de ruptura poderiam, sim, serem benéficas para o mercado de café do Brasil, principalmente quanto à criação de novos produtos industrializados para concorrer com inovações de outros países. Contudo, é importante perceber que a inovação incremental já seria suficiente para melhorar a realidade do setor.

\subsubsection{Ciclo PDCA}

Deve-se considerar o sistema de inovação em café como uma peça administrativa chave, na qual pode ser incluído, por exemplo, o sistema PDCA, amplamente utilizado para gestão de qualidade em setores industriais da economia nacional, que possui exemplos consistentes de aplicação no agronegócio brasileiro (ANJOS, 2011). Esse método de gestão, baseado em repetição, prega que quatro etapas vitais não podem ser desconsideradas na hora de se gerir uma empresa ou 
sistema: planejar, fazer, verificar e corrigir (“plan, do, check, act” formam as letras PDCA), conforme detalhado na Figura 4.

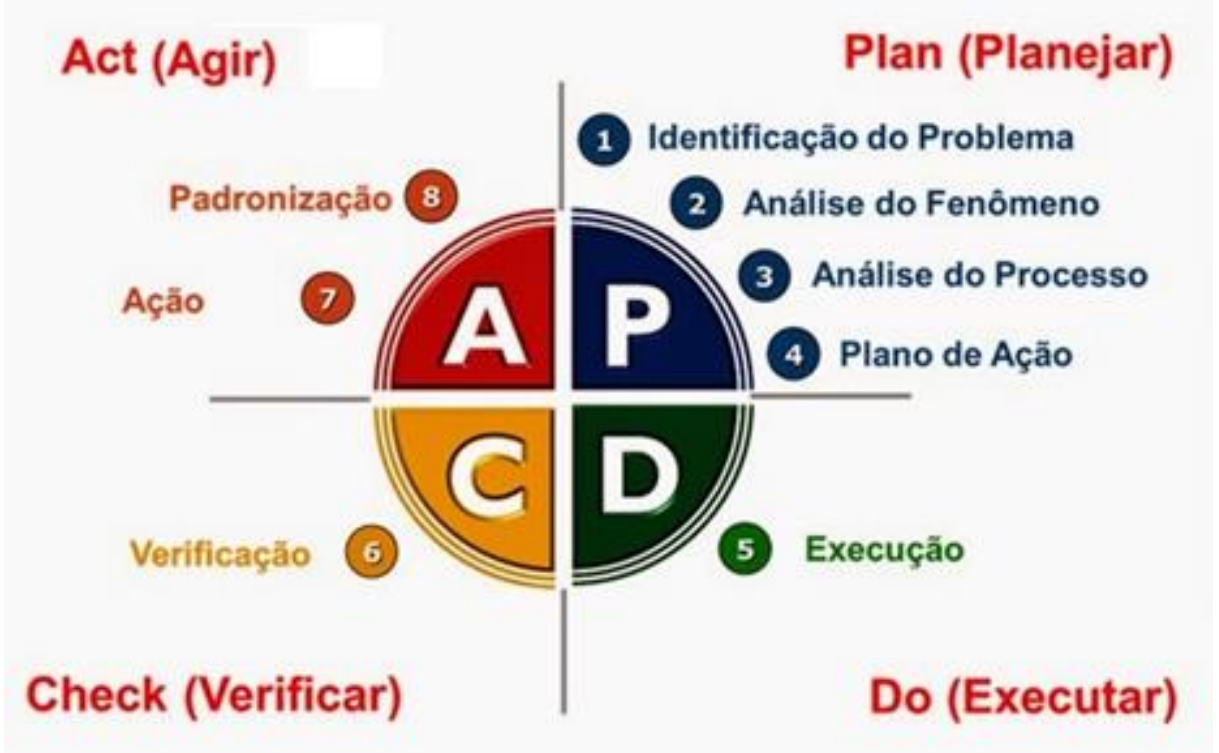

Figura 5 - Ciclo PDCA (Portal Administrador)

É importante que um modelo de inovação considere essas quatro etapas na hora de selecionar os tópicos que serão pesquisados e acompanhe a transferência de tecnologia - deve-se primeiro planejar como o processo será feito, executar a pesquisa, verificar sua viabilidade e agir no sentido de passar o conhecimento para as partes interessadas.

Analisando especificamente as quatro partes do planejamento, tem-se uma ideia processual de como essa etapa do modelo de inovação deveria ser feita. É importante salientar a importância de seus dois primeiros tópicos. Tudo começa pela identificação do problema a ser estudado. Como descrito na seção 2.1.1, não existe muita integração entre os institutos de pesquisa responsáveis pela parte de pesquisa e desenvolvimento e produtores rurais ou mesmo membros da cadeia produtiva de café, com a definição das principais áreas a serem estudadas sendo realizada pela Embrapa, a partir da percepção dos próprios pesquisadores. Como a análise do fenômeno é feita do ponto de vista da academia, é possível que alguns pontos caros à 
parte administrativa da produção de café, como custos para o produtor, necessidade de mão de obra e tempo de retorno de produção não sejam levadas em conta, pelo menos não de forma adequada.

A abordagem pelo ciclo PDCA reforça a importância da participação do produtor rural e de empresas relacionadas ao comércio de café na parte de planejamento.

\subsubsection{Importância da Análise Ambiente Organizacional}

O ambiente de uma organização pode ser dividido em três diferentes níveis, de acordo com o nível de interação dos atores desses com o núcleo da organização. São esses: ambiente interno, ambiente operacional e ambiente contextual. $\mathrm{O}$ primeiro engloba as pessoas diretamente envolvidas na organização (funcionários, administradores), bem como fatores como instalações físicas e cultura organizacional (SOBRAL; 2008, p. 72). Já o segundo contempla elementos que não fazem parte da realidade interna da organização, porém são de direta relevância para o alcance dos objetivos: clientes, fornecedores, bancos e tudo mais que tenha um relacionamento imediato com o núcleo duro da empresa. Por fim, o ambiente contextual engloba elementos que, se não possuem relação direta com a organização, influenciam o seu dia-a-dia mesmo não havendo relação de dependência. São os fatores demográficos, tecnológicos, econômicos, dentre outros. As três camadas estão ilustradas na Figura 4. Segundo Sobral e Peci:

"cabe aos administradores monitorarem e analisarem 0 ambiente organizacional para detectar potenciais oportunidades e ameaças para suas organizações" (SOBRAL; 2008, p. 73).

Devem-se considerar como organizações não apenas empresas como também órgãos públicos, ONGs, autarquias e instituições em geral - qualquer conjunto 
organizado de pessoas que possui um determinado objetivo é, por definição, uma organização.

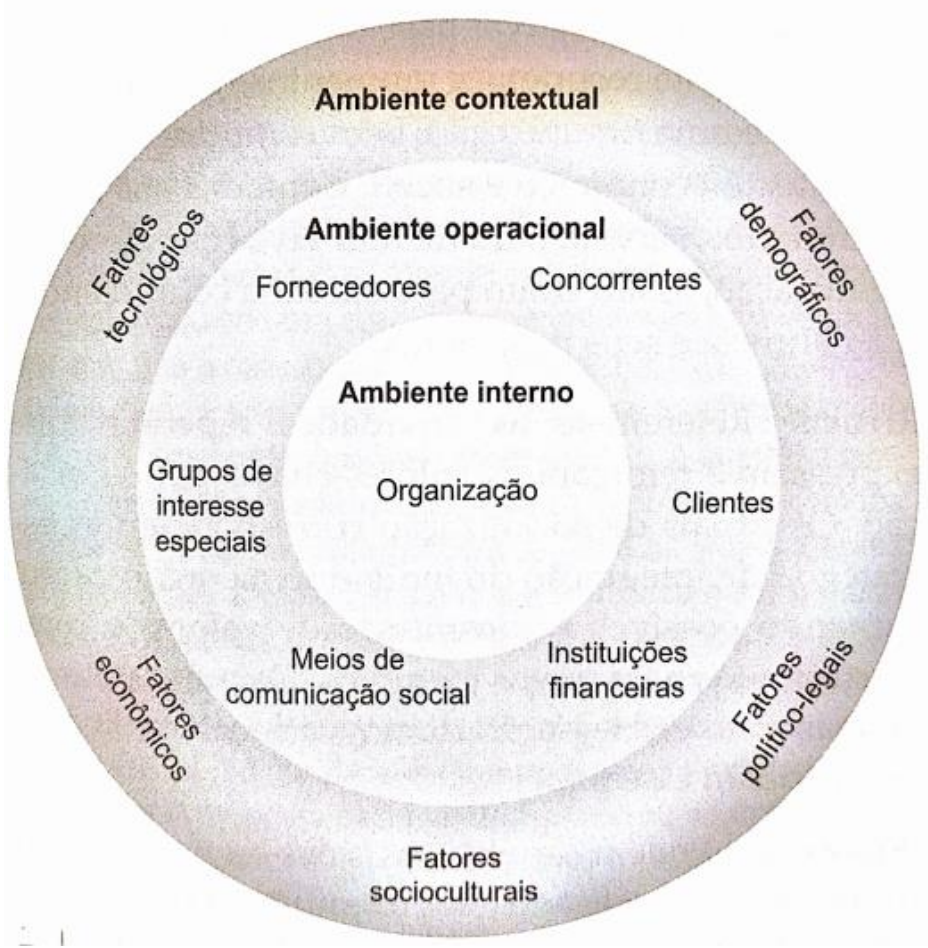

Figura 6 - Tipos de ambiente em uma empresa (SOBRAL e PECI)

Com isso, pode-se afirmar que uma análise detalhada do ambiente organizacional pode servir para reavaliar a forma como o Consórcio de Pesquisa de Café é constituído.

Pode-se considerar como membros do ambiente interno do CDPC todas as suas instituições fundadoras, como universidades (UFV, UFLA), instituições estaduais de apoio rural (EPAMIG, EMATER) e a EMBRAPA.

Como membros do ambiente operacional, estão as entidades federais responsáveis por seu financiamento e organização direta, especialmente o Ministério da Agricultura. Incluem-se aí, também, fornecedores de equipamentos, possíveis terceirizados e outras empresas que se aproveitam diretamente da inovação produzida, principalmente fazendas.

Por último, o ambiente contextual engloba todos os membros da cadeia produtiva de café que não possui influência direta ou relevante no Consórcio: 
exportadoras, indústrias, consumidores finais do produto e representantes de países importadores. 


\section{Solução Proposta}

Este capítulo busca delinear uma proposta de mudanças para o modelo de inovação de café no Brasil, levando em conta principalmente alterações na forma como são decididos os tópicos a serem estudados, no processo de transferência de tecnologia, e no financiamento, com uma maior participação de empresas privadas de exportação, comércio e produção industrial de café nessas funções.

\subsection{Mudanças necessárias}

Como descrito, o modelo atual reserva pouco espaço para empresas de comércio e exportação atuarem em conjunto na decisão sobre inovação. Naturalmente, o foco é voltado para ajudar o produtor rural, que é um ator pulverizado. Além disso, membros da indústria de café não possuem representatividade dentro do Consórcio, e as pesquisas realizadas pela Associação Brasileira de Indústrias de Café são pouco efetivas e sem muita coordenação, haja vista a pouca ou nula importância dada no website da organização.

No contexto específico da Zona da Mata mineira, a situação torna-se mais grave por conta da baixa instrução dos produtores rurais, como apresentado na seção 2.2. Além disso, devido a fatores como a baixa quantidade de indústrias na região e a percepção internacional sobre café local como sendo de baixa qualidade, torna-se essencial inovar para se ajustar o preço médio de venda de café, de modo a melhorar as condições de troca de produtores, comerciantes e exportadores da região.

A situação pede uma solução que integre melhor toda a cadeia produtiva de café, não se limitando somente ao modelo atual de apoio ao produtor rural. 


\subsection{Proposta de mudança}

Três pontos principais necessitam atenção, tanto no nível nacional como no local: 1- pesquisa e desenvolvimento; 2- transferência de tecnologias; 3financiamento. Cada ponto terá suas propostas de mudança explicadas de forma separada.

\subsubsection{Pesquisa e Desenvolvimento}

Sem entrar no mérito de questionar a qualidade dos órgãos responsáveis pela pesquisa em café, principalmente as universidades federais UFV e UFLA, é importante alterar o modelo para colocar indústrias no cerne da discussão sobre que tipo de tecnologias devem ser exploradas.

Apesar de o café ser o segundo maior gerador de riqueza individual do mundo, depois do petróleo (MORAGADO, 2009), grande parte dessa riqueza não beneficia o país pelo fato de o Brasil ser um exportador somente de matéria prima. Além de ajudar produtores rurais com técnicas agrícolas para melhorar sua produção, a pesquisa em café deveria colocar as indústrias no cerne da discussão sobre possíveis investimentos em inovação, de forma a melhorar o processo de torrefação e estimular a criação de produtos de nível superior que possam ser exportados para países com demanda de consumo alta.

A indústria nacional, por razões que incluem a baixa renda do consumidor brasileiro e a forma já tradicional com que grande parte da população consome o produto, não focaliza essas atividades, perdendo uma oportunidade grande de criação de valor. Com isso, o país exporta grãos verdes de café para depois importar cápsulas de café instantâneo, apenas para citar um exemplo.

Uma forma de melhorar esse problema seria colocando a Associação de Indústrias de Café - AIC dentro do arranjo do CDPC, dessa forma estimulando o 
desenvolvimento tecnológico também na indústria, e colocando a inovação tímida que já é ensaiada por essa instituição dentro do arranjo, mais complexo e integrado, do Consórcio.

Também é importante lembrar que o CDPC foi criado no âmbito do Ministério da Agricultura do Brasil, tendo tido, desde suas origens, apenas a produção de grãos como foco.

Com isso, outra forma de trazer para a pauta os processos industriais inovadores que podem alavancar o ganho com café seria aproximar o Consórcio do Ministério da Indústria, Comércio Exterior e Serviços, para ajudar na coordenação e financiamento de iniciativas ligadas ao setor secundário.

\subsubsection{Transferência de Tecnologia}

Quando se produzem tecnologias por instituições governamentais, decisões sobre que técnicas serão produzidas são tão importantes como definir como será o processo de transferência tecnológica. No caso específico da Zona da Mata Mineira, como já explicado, o problema é ainda maior dada a baixa escolaridade do produtor rural.

O fato é que o Consórcio tem uma produção de conteúdo ligada à produção, que é muito rica, principalmente em aspectos como tratamento do solo e análise de produtos, com reconhecimento internacional destacado e técnicas criadas sob organizações pertencentes ao CPDC sendo premiadas em congressos mundiais. A Biblioteca do Café possui uma compilação com todos os artigos produzidos, porém não se pode esperar que o produtor médio tenha interesse e capacidade de decifrar a linguagem científica desse material.

O maior problema, com isso, é garantir que as técnicas sejam aplicadas no campo rural e acompanhadas, visto que pode haver resistência se o resultado não for imediato. Para tal, faz-se necessária a atuação de técnicos e engenheiros agrônomos, 
o que de fato já ocorre com a presença das instituições estaduais de fomento à Agricultura, como a Empresa de Assistência Técnica e Extensão Rural - EMATER.

A realidade, porém, é que na percepção de grande parte dos produtores, esse apoio não é o suficiente. Seria necessário que essas empresas contratassem mais técnicos e engenheiros para que fosse possível se obter um sistema que fosse fragmentado o suficiente para atingir boa parte das fazendas, que, lembrando, são muito pequenas e familiares.

Uma solução para esse problema seria o apoio, na parte de transferência de tecnologia, por parte de empresas compradoras de café (comerciantes e exportadores) com técnicos e engenheiros contratados por eles para fazerem 0 trabalho. O benefício para os produtores é óbvio: um melhor produto com valor de mercado maior. Já o benefício para as empresas compradoras seria o de criar valor para o produto que ela mesma irá comprar, pela obtenção de grãos superiores com melhor aceitação internacional, incluindo cafés especiais, além de criar valor para o cliente, com uma venda consultiva. Além disso, os custos para as instituições de fomento seriam menores se agentes privados se dispusessem a participar da divulgação de técnicas.

A nova organização incluiria essas empresas imediatamente abaixo das instituições estaduais de fomento à agricultura, divulgando, aplicando e acompanhando as melhorias no campo. Já as empresas estaduais deveriam coordenar essas ações de divulgação dentro de suas áreas.

\subsubsection{Financiamento}

O financiamento da inovação de café pelo CPDC, hoje praticamente restrito ao FUNCAFÉ, tem sido, como visto na seção 2.1.4, insuficiente para acompanhar a demanda de crescimento do consórcio e, consequentemente, as necessidades de pesquisa no Brasil. 
Salvo raras exceções, não se encontram empresas de café no Brasil dispostas a investir em inovação, principalmente quando se fala em inovação de ruptura. Parte disso deve-se à dificuldade de se montar uma estrutura interna de pesquisa que possa competir com empresas estrangeiras. Além disso, não existem casos de conglomerados grandes que sejam produtores de café (caso, por exemplo, a Nestlé).

Uma forma de aproximar as indústrias do setor da estrutura de inovação já existente e coordenada pelo CPDC seria por meio do financiamento, tendo a exploração da propriedade intelectual como prêmio. No caso das empresas de comércio e exportação, porém, não seria benéfica para a sociedade que a propriedade intelectual da inovação que poderia ser de interesse delas - a ligada às técnicas de produção - fosse explorada, pois qualquer conhecimento produzido nessa área deveria ter como prioridade a sua difusão plena, ajudando assim um número grande de famílias que depende de sua produção agrícola para sobreviver.

Uma opção para angariar mais recursos por parte dessas empresas de comércio e exportação poderia ser via administração de empréstimos de bancos públicos como o BNDES (VAZ, 2017), o que poderia acontecer tendo como contrapartida o investimento em instituições ligadas ao CPDC, oferecendo taxas mais atrativas para aqueles que o fazem. Empresas exportadoras, por exemplo, utilizam linhas de crédito especiais para manter o capital de giro no intervalo entre a compra do produto no Brasil e o pagamento pela empresa compradora no exterior (processo que, devido ao transporte da mercadoria, pode demorar muitos meses). Seria um incentivo para essas empresas investirem no Consórcio se Ihes fossem oferecidas condições especiais por isso. Além disso, seria uma forma de estimular o investimento sem ter a exclusividade sobre a produção científica como contrapartida, com essa estratégia podendo ser usada para áreas como a pesquisa agrícola. 


\subsection{Aplicabilidade na Zona da Mata Mineira}

Em relação à aplicabilidade das propostas feitas, é necessário dar para a Zona da Mata Mineira uma importância maior quanto à transferência de tecnologia e financiamento. O foco deve ser dado para o setor primário da Economia, visto que, como visto na seção 2.2.1, sobre Inovação na Zona da Mata Mineira, a indústria ainda é muito incipiente na região.

A forma como o setor cafeeiro se organiza na Zona da Mata Mineira, no entanto, mostra que há um grande potencial para empresas de comércio e exportação financiarem e participarem ativamente de ações de transferência da tecnologia de plantio produzida. Algumas companhias já perceberam vantagens comerciais disso, como a exportadora Atlântica Coffee, segunda maior da região em termos de volume comercializado. O diferencial que poderia ser obtido por essas empresas, caso entrassem no Consórcio, seria a obtenção de tecnologia de vanguarda, visto que existe um gap natural entre a produção da tecnologia e sua difusão no meio acadêmico (sem considerar que a maior parte dos técnicos e engenheiros são do mercado e tendem a não ter contato constante com novas técnicas produzidas).

A região deve voltar suas atenções e esforços para a especialização em

produção de grãos de café de qualidade. Como já foi explicado, a área é geograficamente propícia para o surgimento de cafés especiais, e tendo isso em mente, deve-se buscar a aplicação de inovações voltadas para tal. 


\section{Conclusão}

O trabalho teve como objetivos analisar o sistema brasileiro de inovação de café e propor mudanças para se alcançar uma melhora nos níveis de inovação deste setor no Brasil.

Foi feita uma caracterização do Consórcio Brasileiro de Pesquisa de Café, explicando o contexto de sua formação e a forma como atua, principalmente quanto aos aspectos de pesquisa e desenvolvimento, transferência de tecnologia e financiamento. Além disso, a área da Zona da Mata Mineira foi descrita no contexto da inovação de café no Brasil.

Delineou-se uma proposta que incluiu uma série de mudanças no Consórcio de Pesquisa de Café, com o objetivo de melhorar o processo de inovação no setor:

- Participação da Associação Brasileira de Indústrias de Café na decisão sobre o tipo de inovação a ser estudado pelo Consórcio;

- Envolvimento do Ministério da Indústria, Comércio Exterior e Serviços com o Consórcio, passando a colaborar na definição de novos projetos a serem desenvolvidos;

- Participação das empresas de comércio e exportação de café nas ações de transferência de tecnologia, atuando como transmissoras de conhecimento para os produtores rurais de forma pulverizada e ativa;

- Atração de novos investimentos para o Consórcio por parte de empresas privadas, tendo como contrapartida o uso exclusivo da propriedade intelectual obtida durante certo período de tempo.

Esse trabalho conclui que a participação de empresas comerciantes, exportadoras e indústrias de café no processo de inovação dentro do Consórcio de Pesquisa de Café seria vantajosa tanto para essas empresas como para a melhoria desse sistema. Além disso, é percebido que a transferência de tecnologias e técnicas 
agrícolas para o campo por parte de empresas privadas seria de particular importância na Zona da Mata Mineira.

O presente trabalho abre possibilidades para uma análise mais aprofundada de cada um dos aspectos do Consórcio que foram caracterizados. Recomenda-se que, no futuro, sejam feitos estudos semelhantes focados em outros setores produtivos da economia brasileira que já possuam arranjos institucionais de estímulo a inovação, mas que poderiam ser melhorados.

Inovar é essencial para garantir a sobrevivência de organizações em um mundo globalizado e a cada dia mais competitivo. Quando se fala do café, um importante gerador de riqueza coletiva do Brasil, a importância é ainda maior. É necessário continuar discutindo qual o papel das instituições públicas para garantir a competitividade do setor perante o mercado global. Além disso, é imprescindível rever constantemente que ajustes devem ser introduzidos para que esse processo seja otimizado. Apenas um modelo de inovação que permita alterações é possível em contextos de constante mudança. 


\section{Referências Bibliográficas}

ANJOS, M. C. dos. SOUZA, C. C. de; CEZAR, I. M.; ARIAS, E. R. A.; REIS NETO, J. $F$. dos. $O$ uso do método PDCA e de ferramentas da qualidade na gestão da agroindústria no Estado de Mato Grosso do Sul. Revista Agrarian, 2011.

BONATO, José. Acostumado a "Péssima Qualidade", Brasileiro Consome Pouco Café Nobre. UOL Economia, 2013.

CBP\&D/CAFÉ, Consórcio Brasileiro de Pesquisa e Desenvolvimento do Café. Termo de Constituição do Consórcio Brasileiro de Pesquisa e Desenvolvimento do Café. Disponível em http://www.sapc.embrapa.br/arquivos/consorcio/apresentacao/CTermo-de-Constituicao-do-Consorcio-3-3-1997.pdf. 1997.

CECAFÉ, Centro do Comércio de Café do Estado de Minas Gerais. Café: Enquanto o Brasil produz, a Alemanha fatura. Disponível em http://cccmg.com.br/cafe-enquantoo-brasil-produz-a-alemanha-fatura/. 2010

CHRISTENSEN, Clayton; BOWER, Joseph. Disruptive Technologies: Catching the Wave. Harvard Business Review. Vol. 73, № 1. p. 43-53. 1995.

CORNÉLIO, Vanda Maria de Oliveira. Disponibilização de Sementes como Ação Estratégica no Processo de Transferência de Tecnologias. VIII Simpósio de Pesquisa dos Cafés do Brasil. Salvador, 2013.

EMBRAPA, Embrapa Café. Resultados e Dinâmicas do Workshop Fortalecendo a Rede com Novos Projetos do Consórcio Pesquisa Café. Comitê de Publicações da Embrapa Café. $1^{\text {a }}$ ed. Brasília, 2013.

EMBRAPA, Embrapa Café. Relatório de Atividades da Embrapa Café - 2012 a 2015. Disponível em www.sapc.embrapa.br/arquivos/consorcio/publicacoes_tecnicas/. 2015

IBGE, Instituto Brasileiro de Geografia e Estatística. Censo 2010. 2010.

MELO, Maria Angela Campelo. Competitive Innovation in Peripheral Areas: a possible dream? In Proceedings of the VII Triple Helix International Conference, Glasgow, 2009.

MENDES, Paule Jeanne Vieira. Organização da P\&D agrícola no Brasil: evolução, experiências e perspectivas de um sistema de inovação para a agricultura. Campinas, 2009.

Ministério da Agricultura. Balança Comercial do Agronegócio Resumida. Disponível em:<http://www.agricultura.gov.br>. 2016.

MORAGADO, Alice Ane Moreira. Produção de Café no Brasil - Uma Visão de Produção Arábica e Robusta. Revista Cafeicultura. 2009.

PENDERGRAST, Mark. Uncommon Grounds: The History of Coffee and How it Transformed our World. Nova York, 1999

PIRES, Mônica de Moura. Impactos do Crescimento do Consumo de Cafés Especiais na Competitividade Inter-Regional da Atividade Cafeeira. Rev. Econ. Sociol. Rural. Vol. 41, № 3. Brasília, 2003. 
ROMANIELLO, Marcelo Márcio. Avaliação da Ferramenta de Comunicação Rural para a Cafeicultura do Sul do Estado de Minas Gerais: o Caso do Dia de Campo "Café com Leite" na Fazenda Experimental da EPAMIG em Três Pontas. VII Simpósio de Pesquisa dos Cafés do Brasil. Araxá (MG). Disponível em http://www.sbicafe.ufv.br/ (Biblioteca do Café). 2011.

RUTTAN, Vernon W. Usher and Schumpeter on Invention, Innovation, and Technological Change. The Quarterly Journal of Economics. Vol. 73, № 4. p. 596606. Oxford, 1959.

SAEZ, Sylvia. Pequenas Empresas Inovam em Torrefação e Moagem de Café. Folha de São Paulo. São Paulo, 2012.

SCHUMPETER, Joseph. A. Business Cycles: A Theoretical, Historical and Statistical Analysis of the Capitalist Process. McGraw-Hill Book Company. 1a $^{\text {ed. }}$ Nova York, 1939.

SILVEIRA, Alice de Souza. Atributos Sensoriais dos Cafés Cultivados em Diferentes Altitudes e Faces de Exposição na Região das Matas de Minas. Universidade Federal de Viçosa - Dissertações. Viçosa, 2015.

SOBRAL, Felipe; PECl, Alketa. Administração: Teoria e Prática no Contexto Brasileiro. Editora Pearson. $1^{\underline{a}}$ ed. São Paulo, 2008.

THIEMANN, Julia. Germany a coffee giant without growing a single bean. Disponível em:<https://independentaustralia.net/>. 2012.

TOZONI-REIS, Marília Freitas de Campos. Metodologia da Pesquisa. IESDE Brasil. Curitiba, 2007.

VAZ, José Carlos. Café com Inovação. Disponível em https://www.noticiasagricolas.com.br/artigos/artigos-geral/197807-cafe-com-inovacaopor-jose-carlos-vaz.html\#.Wgk3yFWnHIW. Notícias Agrícolas. 2017. 
ANEXO 1. Demonstrativo orçamentário e financeiro - 2012 a 2014

Consórcio Pesquisa Café

Embrapa Café

\begin{tabular}{|c|c|c|c|c|c|c|c|c|c|c|c|c|}
\hline Total do orçamento aprovado e executado & \multicolumn{3}{|c|}{$\begin{array}{l}\text { LOA } 2012 \text { (Lei } 12.595) \\
\text { eio Imvestimento Total }\end{array}$} & \multicolumn{3}{|c|}{$\begin{array}{l}\text { LOA } 2013 \text { (Lei 12.798) } \\
\text { steio Imestimento Total }\end{array}$} & \multicolumn{3}{|c|}{ LOA 2014 (Lei 12.962) } & \multirow{2}{*}{$\begin{array}{c}\begin{array}{c}\text { Total } \\
\text { Custeio }\end{array} \\
21,500.000\end{array}$} & \multirow{2}{*}{$\begin{array}{c}\text { Total } \\
\text { Imvestimerto }\end{array}$} & \multirow{2}{*}{$\begin{array}{c}\begin{array}{c}\text { Total geral } \\
\text { (R\&) }\end{array} \\
\end{array}$} \\
\hline Orçamemo aproado nas LOAs & 9.000 .000 & 3.000 .000 & 12.000 .000 & 7.500 .000 & 2500.000 & 10.000 .000 & 5.000 .000 & 1.500 .000 & 6.500 .000 & & & \\
\hline Descentralizado pelo Mapa a En & 5.421 .818 & 2.578 .182 & 8.000 .000 & 7.500 .000 & 2500.000 & 10.000 .000 & 5.000 .000 & 1.500 .000 & 6.500 .000 & 17.921 .818 & 6.578 .182 & 24.500 .000 \\
\hline Näo descentralizado pelo I & 3.578.182 $>2>0$ & 421.818 & 4.000 .000 & - & - & 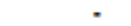 & & & & 3.578. 182 & 421.818 & 4.000 .000 \\
\hline Saldo decolvido ao Mapa (ng & 401.004 & 1.000 & 402.004 & & & & 81.153 & & 81.153 & 482.157 & 1.000 & 483.157 \\
\hline Total geral executado & 5.020 .814 & 2.577 .182 & 7.597 .998 & 7.500 .000 & 2.500 .000 & 10.000 .000 & 4.918 .847 & 1.500 .000 & 6.418 .847 & 17.439 .661 & 6.577 .182 & 24.016 .843 \\
\hline Total executa do por instituição consorcia da & Custeio & Imvestimento T & Total no ano & Custeio & Imestimento & Total no ano & Custeio & Imvestimento & Total no ano & $\begin{array}{l}\text { Total } \\
\text { Custeio }\end{array}$ & $\begin{array}{c}\text { Total } \\
\text { Imvestimento }\end{array}$ & $\begin{array}{c}\text { Total geral } \\
\text { (RS) }\end{array}$ \\
\hline Instituiçōes Federais de Ensino & & & & & & & & & & $\dot{\circ}$ & : & \\
\hline $\begin{array}{l}\text { Universidade Federal de Lavas - UFLA } \\
\text { Universidade Federal do Espinito Santo-UFES }\end{array}$ & $\begin{array}{l}43.238 \\
15.699\end{array}$ & & $\begin{array}{l}43.238 \\
15.699\end{array}$ & $\begin{array}{r}252.232 \\
53.974\end{array}$ & & $\begin{array}{r}252.232 \\
53.974\end{array}$ & 216.345 & & $\begin{array}{c}216.345 \\
\cdot\end{array}$ & $\begin{array}{r}511.815 \\
69.673\end{array}$ & $:$ & $\begin{array}{r}511.815 \\
69.673\end{array}$ \\
\hline $\begin{array}{l}\text { Instituto Federal de Educaç3o, Ciencia e Tecnologia do Sul de } \\
\text { Minas Gerais - Campus Machado - IFSM }\end{array}$ & 6.348 & & 6.348 & & & $\cdot$ & & & $\cdot$ & 6.348 & $\cdot$ & 6.348 \\
\hline Instituto Federal de Educaçäo, Ciencia e Tecnologia do Triangulo & & & & & & & & & & & & \\
\hline $\begin{array}{l}\text { Mineiro - Campus Uberaba - IFTM } \\
\text { Universidade Federal de Viçosa . }\end{array}$ & 10.772 & & 10.772 & & & 26.496 & & & - & 10.772 & : & 10.772 \\
\hline $\begin{array}{l}\text { Universide } \\
\text { Subtotal }\end{array}$ & 76.057 & . & 76.057 & $\begin{array}{r}26.496 \\
332.703\end{array}$ & & $\begin{array}{r}26.496 \\
332703\end{array}$ & 216.345 & & 216.345 & $\begin{array}{r}26.496 \\
625.105\end{array}$ & : & $\begin{array}{r}26.496 \\
625.106\end{array}$ \\
\hline$\underline{\text { Subtotal }}$ & & & $76.00 \mathrm{r}$ & 30.103 & & 332.03 & 216.340 & & 210.340 & 625.105 & & 625.105 \\
\hline \multicolumn{13}{|l|}{ nstituiçōos E E } \\
\hline Secretaria de Agricultura e Abastecimento do Estado de Săo Paulo & 483.688 & & 483.668 & 1.753 .902 & 400.000 & 2.153 .902 & 50.000 & 200.000 & 250.000 & 2.287 .570 & 600.000 & 2.887 .570 \\
\hline $\begin{array}{l}\text { Empresa de Pesquisa Agropecuarria de Minas Gerais - EPAMIG } \\
\text { nstituto Agronbrmico do Parana - IAPAR }\end{array}$ & $\begin{array}{l}472.616 \\
337.772\end{array}$ & 486.700 & $\begin{array}{l}969.316 \\
337.772\end{array}$ & $\begin{array}{l}1.532 .054 \\
1.543 .658\end{array}$ & 350.000 & $\begin{array}{l}1.532 .054 \\
1.893 .658\end{array}$ & & $\begin{array}{l}252.900 \\
150.000\end{array}$ & $\begin{array}{l}252.900 \\
150.000\end{array}$ & $\begin{array}{l}2.004 .670 \\
1.881 .430\end{array}$ & $\begin{array}{l}739.600 \\
500.000\end{array}$ & $\begin{array}{l}2.744 .270 \\
2.381 .430\end{array}$ \\
\hline Instituto Capixaba de Pesquisa, Assisténcia & & & & & & & & & & & & \\
\hline $\begin{array}{l}\text { Rural INCAPER } \\
\text { Empresa de Pes }\end{array}$ & 147.679 & & 147.679 & 716.859 & 320.000 & 1.038 .859 & & 150.000 & 150.000 & & 470.000 & 1.334 .538 \\
\hline Empresa de Pe & & & & & & & 32.000 & & 32.000 & 32000 & & 32.000 \\
\hline Univers: & $\begin{array}{r}156.267 \\
18750\end{array}$ & & ${ }_{185.267}^{155}$ & $\begin{array}{r}113.863 \\
18750\end{array}$ & & $\begin{array}{r}113.863 \\
18.750\end{array}$ & & & : & $\begin{array}{r}269.130 \\
37500\end{array}$ & : & 269.130 \\
\hline Univers & 18.750 & & 18.750 & 18.750 & & 18.750 & & & - & 37.500 & - & 37.500 \\
\hline Universidade Estadual do S & & & - & 37.125 & & 37.125 & & & - & 37.125 & - & 37.125 \\
\hline $\begin{array}{l}\text { Empresa de Assistencia Técrica e Extensão Rural do Estado de } \\
\text { Minas Gerais - EMATER/MG }\end{array}$ & 883.880 & & 883.880 & & & $\cdot$ & & & - & 883.880 & - & 883.880 \\
\hline Instituto Paranaense de Assistencia Térica e Extensăo Rural - & & & & & & & & & & & & \\
\hline $\begin{array}{l}\text { EMATER/ } \\
\text { Subtotal }\end{array}$ & & 87007 & 5 & $\begin{array}{r}128.410 \\
5\end{array}$ & & $\begin{array}{r}128.410 \\
-1010\end{array}$ & & & $m$ & $\begin{array}{r}128.410 \\
-10\end{array}$ & 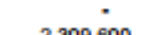 & $\begin{array}{r}128.410 \\
7\end{array}$ \\
\hline$\underline{\text { Subtotal }}$ & 2.499 .632 & $6.700^{\circ}$ & 2.986 .332 & 5.844 .621 & $1.070 .000^{\circ}$ & 6.914 .621 & 82.000 & 752.900 & 834.900 & 8.426 .253 & 2.309 .600 & 10.735 .853 \\
\hline \multicolumn{13}{|l|}{ Embrap } \\
\hline $\begin{array}{l}\text { Embrape } \\
\text { Subtota }\end{array}$ & 2.445 .125 & 090.482 & 4.535 .607 & 1.322 .676 & & $\begin{array}{l}2.752 .676 \\
\end{array}$ & & & & 6.337.492 & 4.267.582 & 10.605.074 \\
\hline Subtotal & 2.445 .125 & 2.090 .482 & 4.535 .607 & 1.322 .676 & 1.430 .000 & 2.752 .676 & 2.569.691 & 747.100 & 3.316 .791 & 6.337 .492 & 4.267.582 & 10.605 .074 \\
\hline \\
\hline Fundaçăo de Apoio a Pesquis & & & - & & & - & 1.86 & & .809 & 99 & - & 109 \\
\hline Indaçăo de Apoio a Tec & & & $\boldsymbol{r}$ & & & $=$ & & & & & - & 3.002 \\
\hline Subtotal & $\cdot$ &. & $=$ & $\dot{-}$ &. & $=$ & 2.050 .811 & $\cdot$ & 2.050 .811 & 2.060 .811 & - & 2.050 .811 \\
\hline otalg g & 0.814 & .182 & .99 & 0.000 & .000 & 0.000 & 84 & 0.00 & .418 .847 & 7.439.661 & 7.182 & 24.016 .843 \\
\hline
\end{tabular}

Tabela 1 - Demonstrativo Orçamentário e Financeiro do Consórcio Brasileiro de Pesquisa de Café - 2012 a 2014 